\title{
Greenhouse Gas Emissions Payback for Lightweighted Vehicles Using Aluminum and High-Strength Steel
}

\author{
Hyung-Ju Kim, Colin McMillan, Gregory A. Keoleian, \\ and Steven J. Skerlos
}

\section{Keywords:}

automobile

industrial ecology

life cycle assessment (LCA)

light metal

material substitution

recycling

:// Supporting information is available on the JIE Web site

\author{
Address correspondence to: \\ Dr. Hyung-Ju Kim \\ Department of Mechanical Engineering \\ College of Engineering \\ University of Michigan \\ 2250 GG Brown Building \\ 2350 Hayward Street \\ Ann Arbor, MI 48109, USA \\ kimhyung@umich.edu \\ www.engin.umich.edu/labs/east/ \\ (c) 2010 by Yale University \\ DOI: $10.1111 /$ j.1530-9290.2010.00283.x
}

I

\section{Summary}

In this article we consider interactions between life cycle emissions and materials flows associated with lightweighting (LW) automobiles. Both aluminum and high-strength steel (HSS) lightweighting are considered, with LW ranging from $6 \%$ to $23 \%$ on the basis of literature references and input from industry experts. We compare the increase in greenhouse gas (GHG) emissions associated with producing lightweight vehicles with the saved emissions during vehicle use. This yields a calculation of how many years of vehicle use are required to offset the added GHG emissions from the production stage. Payback periods for HSS are shorter than for aluminum. Nevertheless, achieving significant LW with HSS comparable to aluminum-intensive vehicles requires not only material substitution but also the achievement of secondary LW by downsizing of other vehicle components in addition to the vehicle structure. GHG savings for aluminum LW varies strongly with location where the aluminum is produced and whether secondary aluminum can be utilized instead of primary. HSS is less sensitive to these parameters. In principle, payback times for vehicles lightweighted with aluminum can be shortened by closed-loop recycling of wrought aluminum (i.e., use of secondary wrought aluminum). Over a 15-year time horizon, however, it is unlikely that this could significantly reduce emissions from the automotive industry, given the challenges involved with enabling a closed-loop aluminum infrastructure without downcycling automotive body structures.

Volume 14, Number 6 


\section{Introduction}

Emissions of greenhouse gases (GHGs) from human activities have led to a marked increase in atmospheric GHG concentrations. Global anthropogenic emissions grew 70\% between 1970 and 2004 (IPCC 2007). Even with climate change mitigation policies and related sustainable development practices, global GHG emissions are expected to continue growing over the next few decades (IPCC 2007). The Intergovernmental Panel on Climate Change (IPCC) indicates that there is substantial economic potential for the mitigation of GHG emissions over the coming decades that could offset the projected growth of global emissions or reduce emissions below current levels (IPCC 2007). If the concentration of GHGs in the atmosphere is to stabilize, emissions need to peak and then decline. The lower the stabilization level to be achieved is in GHG concentration, the more quickly this peak and decline need to occur. Mitigation efforts over the next 2 or 3 decades will have a large impact on opportunities to achieve lower stabilization levels (IPCC 2007).

Recent policy proposals aimed at reducing GHG emissions from automobiles have accelerated efforts to significantly improve vehicle fuel efficiency. One option is to reduce the overall mass of vehicles. Lightweighting (LW) of vehicles presents an opportunity for simultaneously cutting petroleum consumption and GHG emissions. Among the potential LW materials, highstrength steel (HSS) and aluminum have been proven to achieve weight reduction while meeting vehicle safety and performance requirements. Despite the potential LW advantages of these metals, their displacement of traditional materials, such as mild steels, ${ }^{1}$ has been slow due to their higher costs, manufacturing challenges, and institutional as well as technical barriers.

Available studies of lightweight vehicles from the literature are summarized in table 1 . Some of the first popular aluminum-intensive vehicles (AIVs) were produced by Audi (models A8 and A2) and Jaguar (model XJ; Scamans 2005; Henn and Leyers 2006). In one case, a Ford AIV project achieved a body-in-white (BIW) mass of 205 kilograms $(\mathrm{kg}){ }^{2}$ which was $136 \mathrm{~kg}$ lighter than its baseline vehicle (Ford Taurus). BIW is the stage in which the car body sheet metal (including doors, hoods, and deck lids) has been assembled or designed but before the components (chassis, motor) and trim (windshields, seats, upholstery, electronics, etc.) have been added (Babylon 2009). Taken together, the examples in table 1 reveal the technical possibility of reducing the curb weight (i.e., the weight of a motor vehicle with standard equipment, maximum capacity of liquids [Babylon 2009]) of vehicles by $11 \%$ to $25 \%$ through aluminum substitutions alone. Primary mass reduction makes it possible to further reduce vehicle weight by downsizing other components (e.g., engine, fuel tank), given the inherently higher efficiency of lighter vehicles. This subsequent weight reduction is defined as secondary mass reduction. In table 1 , secondary lightweighting effects by the AIVs were not reported.

HSS provides an alternative to aluminum lightweighting. An ongoing detailed analysis of HSS has been performed through the Ultralight Steel Auto Body (ULSAB) project, a consortium of 35 steel manufacturers from 18 countries active in the period 1994-1998 (Obenchain et al. 2002). One of its first achievements was to demonstrate that HSS can both reduce body mass and improve stiffness simultaneously. In the original ULSAB project, a BIW weight reduction of $68 \mathrm{~kg}$ (from $271 \mathrm{~kg}$ to $203 \mathrm{~kg}$ ) was achieved from benchmarked vehicles in the concept phase of the study (Obenchain et al. 2002; Wallentowitz et al. 2006). Because HSS has the same density as steel, the increased strength of loadbearing components means less steel is required for an equivalent function when compared to aluminum. Nonetheless, using HSS as a substitute for nonloading applications has no advantage relative to aluminum, because the option to use less material for a given function is not likely to exist. Substituting aluminum for steel in nonload-bearing applications does provide an advantage due to the lower density of aluminum relative to steel. Given the similar densities of HSS and mild steel, achieving intensive lightweighting through HSS requires significant reliance on secondary lightweighting enabled by primary mass reductions. For instance, in the ULSAB Advanced Vehicle Concepts (ULSABAVC) project, based on a compact-class vehicle, ${ }^{3}$ 


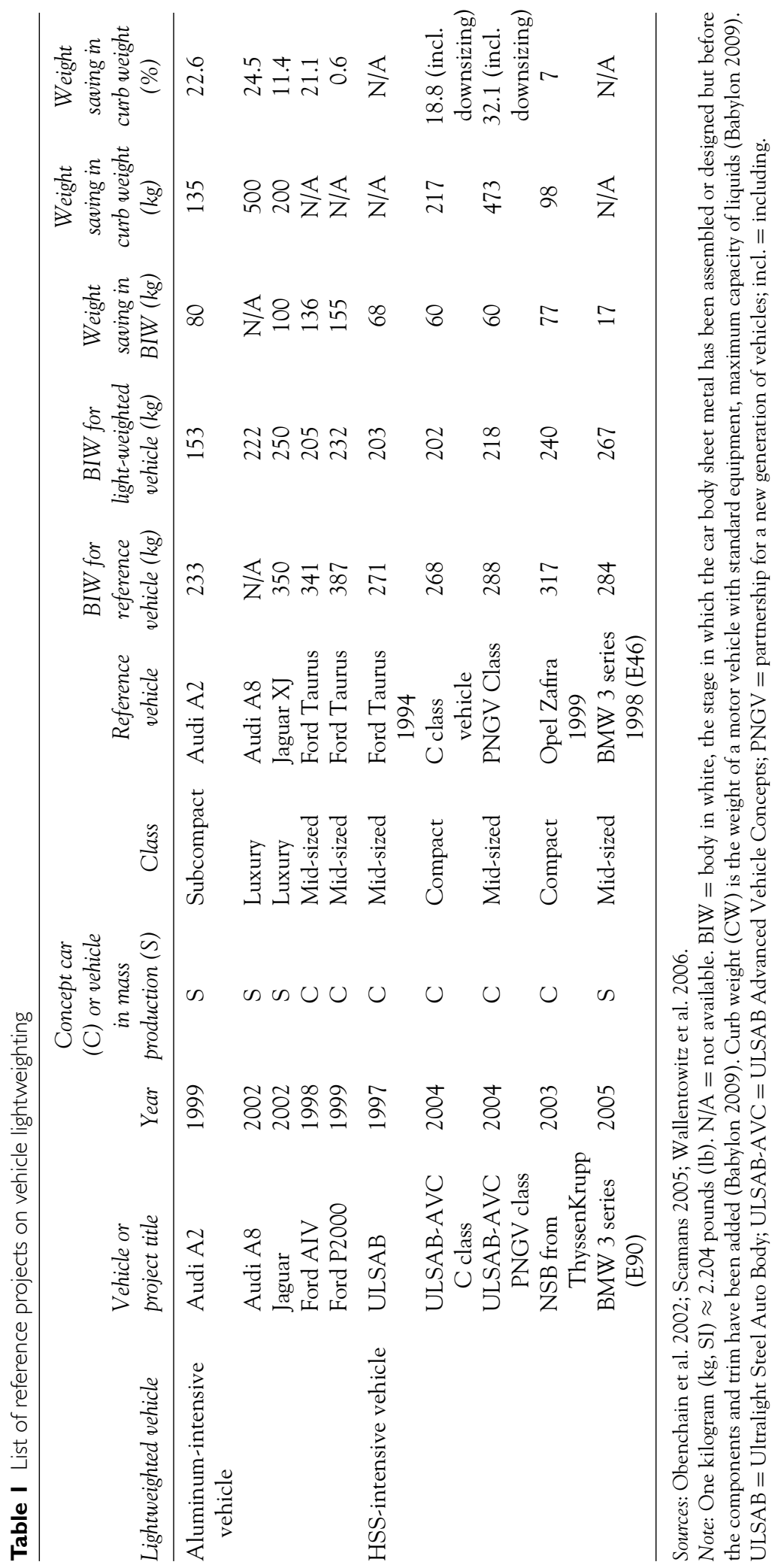


a curb-weight lightweighting of $18.8 \%$ was achieved when secondary weight reductions due to component downsizing were included (Obenchain et al. 2002; Wallentowitz et al. 2006).

From the emissions perspective, HSS has a much lower GHG footprint per kilogram than primary aluminum (Tessieri and $\mathrm{Ng} 1995 ; \mathrm{Ng}$ et al. 1999; Zapp et al. 2003). Therefore, the literature has been more concerned about the environmental impacts of AIVs. A common conclusion in the literature is that AIVs should be accompanied by the creation of a closed-loop recycling system for the resulting end-of-life (EoL) scrap (Tessieri and Ng 1995; Ng et al. 1999). Life cycle assessment (LCA) studies today for AIVs generally assume a closed-loop recycling of the aluminum alloys used in the vehicle structure and powertrain (e.g., Tessieri and Ng 1995). Although this recycling is possible in theory, in practice it is not possible to produce wrought aluminum from recycled material in the automotive industry due to economics and a lack of infrastructure. For this reason, AIVs (and HSS vehicles) initially require the input of primary metals because of a lack of available infrastructure for producing secondary wrought metals that can be used in the vehicle structure. In this article, we consider the life cycle emissions of AIVs both with and without a closed-loop infrastructure for wrought aluminum materials, for comparative purposes.

Although previous research has studied the maximum achievable magnitude of vehicle lightweighting using aluminum and HSS (Das et al. 1997; $\mathrm{Ng}$ et al. 1999; Das 2000a, 2000b; IAI 2000; Austin et al. 1999; Obenchain et al. 2002; Wallentowitz et al. 2006), only a few studies have been performed to investigate the tradeoffs between aluminum and HSS. These articles (Dieffenbach and Mascarin 1993; Han and Clark 1995; Han 1996; Kelkar et al. 2001; Geyer 2008) concentrated on economic and environmental impacts of steel and aluminum BIW. They did not, however, cover the whole vehicle-only the BIW. Furthermore, these investigations did not consider the context of a specific vehicle for which emissions calculations for the use phase followed from a detailed engineering model. In the present article, we develop the analysis in the context of a specific vehicle to provide a com- plete picture of the magnitude of GHG trade-offs between aluminum and HSS for a real vehicle, absent the assumption of a closed-loop aluminum infrastructure that is decades away. The article therefore provides an indication of the importance of production versus use-phase trade-offs in the context of meeting societal goals for reducing GHG emissions from the automotive sector, as well as the time frames over which these benefits can be achieved.

The life cycle model developed in this article begins to answer the following questions:

- What are the life cycle emissions reductions associated with different levels of LW when aluminum versus HSS is used for a specific compact-sized vehicle?

- How does the comparison change with the introduction of a closed-loop wrought material recycling system for aluminum, and with attention to where the primary material was produced?

- Are the GHG payback periods significant relative to the time scales over which emissions reductions are needed from the passenger vehicle industry?

To answer these questions in a realistic scenario, we evaluate life cycle GHG emissions for a range of $\mathrm{LW}$, production carbon intensity, and end-of-life vehicle management scenarios for both aluminum and HSS. We begin the next section by describing the detailed LW modeling of a specific compact vehicle and then offer a sensitivity analysis for key assumptions employed in the system model.

\section{Methods and Models}

Our baseline vehicle is based on a compactsized Ford Focus ZX3 (Model 2000 2004 with initial curb weight $1,159 \mathrm{~kg}$ ). We assume the baseline vehicle BIW subassembly has a primary lightweighting potential of up to $11 \%$ with aluminum, on the basis of analysis by Nathani and Arnsberg (2002) and Neumann and Schindler (2002), and up to $6 \%$ with HSS, on the basis of work by Wallentowitz and colleagues (2006). We also assume that lightweighting with aluminum beyond the BIW can achieve a total curb weight 
reduction of up to $23 \%$ relative to the baseline vehicle (Wallentowitz et al. 2006).

In addition to this primary weight reduction, secondary weight reductions are also considered. Secondary weight reductions can be achieved when reducing the weight of a given vehicle subsystem allows weight savings in supporting vehicle subsystems. Because of the dependency of secondary weight saving on the primary weight saving, a weight-saving factor as the quotient of the two percentages can be calculated. In three literature sources, a 2:1 ratio for the primary to the secondary weight saving is claimed (Das 2000a, 2000b; Gaines and Cuenca 2002; Wallentowitz et al. 2002). Another literature source, however, claimed a $3.0 \%$ to $8.2 \%$ fuelsaving effect due to secondary weight reduction by powertrain redesigns (Wohlecker et al. 2007). In the present article, we applied a $3.0 \%$ to $8.2 \%$ fuel-saving effect, because of a lack of data to support the 2:1 assumption and according to the advice and experience of a materials expert working at one of the major U.S. automakers.

On the basis of a detailed survey of the components and material composition of a generic compact-sized vehicle described in the literature ( $\mathrm{Ng}$ et al. 1999), we created five LW options with aluminum and HSS. These LW options are as follows (percentages are with reference to curb weight):

- $6 \%$ LW with HSS

- $6 \% \mathrm{LW}$ with aluminum

- $11 \%$ LW with aluminum

- $19 \%$ LW with HSS (Obenchain et al. 2002; Wallentowitz et al. 2006), including secondary weight reductions from component downsizing

- $23 \% \mathrm{LW}$ with aluminum.

To understand the GHG emissions of these LW vehicles relative to their baseline compact vehicle, we needed to create the analysis models that are described in the following sections:

- component-level material model

- fuel economy performance and vehicle miles traveled (VMT) $)^{4}$ models

- life cycle GHG emissions and EoL ${ }^{5}$ materials recovery models.

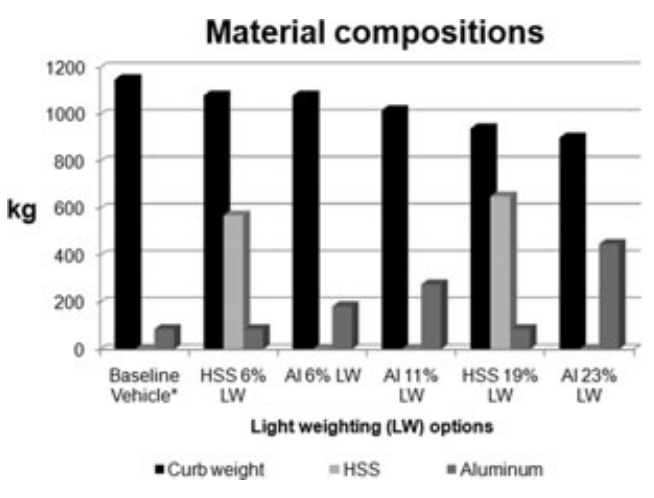

Figure I Material composition for the baseline vehicle and five lightweighting options. $\mathrm{kg}=$ kilogram; HSS = high-strength steel; $\mathrm{Al}=$ aluminum.

\section{Component-Level Material Model}

We began by evaluating the magnitude of vehicle lightweighting that is technologically feasible and then calculating the associated mass of aluminum or HSS required. Starting with a curb weight of $1,159 \mathrm{~kg}$ for the baseline vehicle, we estimated that the baseline vehicle has a steel/iron mass of $737 \mathrm{~kg}$, a light metals ${ }^{6}$ mass of $115 \mathrm{~kg}$, and an aluminum mass of $86 \mathrm{~kg}$ (Tessieri and Ng 1995; Nathani and Arnsberg 2002). From here, we performed a most-likely material analysis at the component level for the baseline vehicle components. For verification purposes, we confirmed that the sum of the component material masses was approximately equal to the known mass of each material in the vehicle. Given a realistic component-level material model of the baseline vehicle, it was possible to lightweight the vehicle, given the opportunity to substitute each major component of the vehicle with either aluminum (Tessieri and Ng 1995; Austin et al. 2002; Neumann and Schindler 2002) or HSS (Das et al. 1997; Das 1999). Figure 1 provides the detailed material compositions of the baseline vehicle and each LW scenario considered in this work.

As mentioned above, we performed component-level and subsystem-level analyses to ensure feasible weight reductions and inputs of LW materials. In other words, we verified every kilogram of additional lightweighting beyond the baseline vehicle to ensure feasibility. 
Table 2 Substitution of materials for vehicle components with respect to lightweighting (LW) options

\begin{tabular}{|c|c|c|c|c|c|c|c|c|c|}
\hline \multirow[b]{2}{*}{ Component } & \multirow{2}{*}{$\begin{array}{l}\text { Quantity } \\
\text { per } \\
\text { vehicle }\end{array}$} & \multirow{2}{*}{$\begin{array}{c}\text { Total } \\
\text { weight as } \\
\text { aluminum }(\mathrm{kg})\end{array}$} & \multirow{2}{*}{$\begin{array}{c}\text { Total } \\
\text { weight as } \\
\text { HSS }(\mathrm{kg})\end{array}$} & & $\begin{array}{l}L W \\
6 \%\end{array}$ & $\begin{array}{l}L W \\
6 \%\end{array}$ & $\begin{array}{l}L W \\
11 \%\end{array}$ & $\begin{array}{l}L W \\
19 \%\end{array}$ & $\begin{array}{l}L W \\
23 \%\end{array}$ \\
\hline & & & & \multicolumn{3}{|c|}{ Baseline HSS aluminum } & aluminum & \multicolumn{2}{|c|}{ HSS aluminum } \\
\hline \multicolumn{10}{|l|}{$\begin{array}{l}\text { (A) Powertrain } \\
\text { (1) Engine }\end{array}$} \\
\hline $\begin{array}{l}\text { Balance shaft } \\
\text { carrier }\end{array}$ & 1 & 2.5 & 4.4 & & & & & $\sqrt{ }$ & \\
\hline Belt tensioner & 1 & 0.8 & 1.4 & & $\sqrt{ }$ & & & $\sqrt{ }$ & \\
\hline Brackets & 1 & 1.2 & 2.1 & & $\sqrt{ }$ & & $\sqrt{ }$ & $\sqrt{ }$ & $\sqrt{ }$ \\
\hline $\begin{array}{l}\text { Catalytic converter } \\
\text { heat shield }\end{array}$ & 1 & 0.5 & 1.0 & $\sqrt{ }$ & & $\sqrt{ }$ & $\sqrt{ }$ & & $\sqrt{ }$ \\
\hline Chain case & 1 & 2.7 & 4.9 & & & & $\sqrt{ }$ & & $\sqrt{ }$ \\
\hline Cylinder head & 2 & 12.7 & 22.9 & $\sqrt{ }$ & & $\sqrt{ }$ & $\sqrt{ }$ & & $\sqrt{ }$ \\
\hline Cylinder liner & 6 & 2.7 & 4.9 & & $\sqrt{ }$ & & & $\sqrt{ }$ & \\
\hline Engine block & 1 & 18.2 & 32.7 & & & & & $\sqrt{ }$ & \\
\hline Fuel filling rail & 1 & 0.5 & 0.8 & & $\sqrt{ }$ & & $\sqrt{ }$ & $\sqrt{ }$ & $\sqrt{ }$ \\
\hline Intake manifold & 1 & 4.5 & 8.2 & & $\sqrt{ }$ & & & $\sqrt{ }$ & \\
\hline Oil filter adapter & 1 & 0.2 & 0.3 & & & & $\sqrt{ }$ & & $\sqrt{ }$ \\
\hline Oil pan & 1 & 3.2 & 5.7 & & & & $\sqrt{ }$ & & $\sqrt{ }$ \\
\hline $\begin{array}{l}\text { Oil pump } \\
\text { body/cover }\end{array}$ & 1 & 1.5 & 2.6 & & $\sqrt{ }$ & & $\sqrt{ }$ & $\sqrt{ }$ & $\sqrt{ }$ \\
\hline Pistons & 6 & 3.3 & 5.9 & $\sqrt{ }$ & & $\sqrt{ }$ & $\sqrt{ }$ & & $\sqrt{ }$ \\
\hline Rocker/cam covers & 1 & 1.6 & 2.9 & & $\sqrt{ }$ & & $\sqrt{ }$ & $\sqrt{ }$ & $\sqrt{ }$ \\
\hline Rocker arm & 1 & 0.9 & 1.6 & & $\sqrt{ }$ & & & $\sqrt{ }$ & \\
\hline $\begin{array}{l}\text { Rocker assembly } \\
\text { pedestals }\end{array}$ & 1 & 1.8 & 3.3 & & $\sqrt{ }$ & & & $\sqrt{ }$ & \\
\hline $\begin{array}{l}\text { Starter motor nose } \\
\text { housing }\end{array}$ & 1 & 0.6 & 1.1 & & $\sqrt{ }$ & & $\sqrt{ }$ & $\sqrt{ }$ & $\sqrt{ }$ \\
\hline $\begin{array}{l}\text { Super charger } \\
\text { cover/bedring } \\
\text { plate }\end{array}$ & 1 & 2.5 & 4.6 & & & & & $\sqrt{ }$ & \\
\hline $\begin{array}{l}\text { Super charger } \\
\text { housing }\end{array}$ & 1 & 7.4 & 13.3 & & & & & $\sqrt{ }$ & \\
\hline Super charger rotor & 1 & 3.0 & 5.5 & & & & & $\sqrt{ }$ & \\
\hline Throttle body & 1 & 0.7 & 1.3 & & $\sqrt{ }$ & & & $\sqrt{ }$ & \\
\hline $\begin{array}{l}\text { Timing chain } \\
\text { cover/front cover }\end{array}$ & 1 & 1.7 & 3.0 & & $\sqrt{ }$ & & $\sqrt{ }$ & $\sqrt{ }$ & $\sqrt{ }$ \\
\hline Turbo intake & 1 & 2.3 & 4.1 & & $\sqrt{ }$ & & & $\sqrt{ }$ & \\
\hline $\begin{array}{l}\text { Water pump } \\
\text { assembly }\end{array}$ & 1 & 1.4 & 2.5 & $\sqrt{ }$ & & $\sqrt{ }$ & $\sqrt{ }$ & & $\sqrt{ }$ \\
\hline
\end{tabular}

Note: Check marks indicate substitution into the light metals. HSS = high-strength steel.

An example of how this was done is provided in table 2. Table 2 is an excerpt of a larger table that includes all major vehicle components and subsystems for which lightweighting is an option in the baseline vehicle. For example, table 2 shows that the engine cylinder head is already assumed to be aluminum in the baseline vehicle. Therefore, it is not a candidate for additional lightweighting. Aluminum engine brackets, however, are not assumed in the baseline vehicle and are therefore applied in the $11 \%$ LW and more intensive options. Similarly, the steel balance shaft carrier is replaced by aluminum in the $19 \% \mathrm{LW}$ option. We prioritized 
applications of LW by applying lowest-cost material substitutions first. The complete version of table 2, found as Table S-3 in the Supporting Information on the Web, also lists the most likely manufacturing process assumed (on the basis of publications by Tessieri and $\mathrm{Ng}$ 1995) for producing the aluminum components-among casting, flat rolling, extrusion, and forging. This was required to estimate manufacturing GHG emissions from the production of LW components.

In this study, mild steel 140/270 (material price: $^{7} \$ 0.80 / \mathrm{kg}$; scrap price: $\$ 0.10 / \mathrm{kg}$; density: $7.85 \mathrm{~g} / \mathrm{cc}$ ) and HSSs (material price: $\$ 0.85$ to $\$ 0.95 / \mathrm{kg}$; scrap price: $\$ 0.10 / \mathrm{kg}$; density: 7.85 $\mathrm{g} / \mathrm{cc}$ ), such as Brinell Hardness (BH) 260/370e, high strength low alloy (HSLA) 350/450, or dual phase (DP) 350/600e, are used as reference materials for the material modeling. These HSSs are assumed to have a $10 \%$ weight reduction potential in load-bearing applications over their conventional counterparts. The information was provided by a delegation from the International Iron and Steel Institute (IISI) (Opbroek 2007).

In this research, we assumed a most probable alloy type for each component on the basis of research by Tessieri and $\mathrm{Ng}$ (1995). We needed to do this to understand which components can be sorted and recycled together while avoiding downcycling. For example, the balance shaft carrier was assumed to be produced from $100 \%$ of aluminum alloy 356. Aluminum engine brackets are produced from $12 \%$ of aluminum alloy 319 and $88 \%$ of aluminum alloy 380 . This means that disassembly of the shaft carrier from the brackets, as well as the separation of brackets, would be necessary for a closed-loop material management system to avoid alloy mixing and resultant downcycling. This has significant ramifications for the ultimate cost, although not the technical feasibility, of a closed-loop aluminum infrastructure.

\section{Fuel Economy Performance of LW Vehicles}

Our estimates of GHG emissions from the use phase require two major elements: an estimate of miles per gallon (mpg ${ }^{8}$; also known as fuel economy) under various lightweighting strategies, and an assumption about VMT. Here we use the VMT model by Das (2000a, 2000b), summarized in Supporting Information Part D, available on the Web. Fuel consumption per mile was determined with the simulation software AVL Cruise (AVL LIST GmbH) for each LW option. In the model, only vehicle weight affects the fuel economy (material type used to achieve a given weight does not matter). The model assumes that VMT is the same for all vehicles (181,195 miles).

As shown in figure 2, AVL Cruise calculates that the baseline vehicle has a fuel economy of 33.0 miles per gallon (mpg) for the Federal Test Procedure-75 (FTP75; the drive cycle that is the most common fuel economy metric in the United States and used for regulation). The fuel economy is increased to $34.2 \mathrm{mpg}$ in the $6 \%$ LW option and further increased to $35.1 \mathrm{mpg}$, $36.7 \mathrm{mpg}$, and $37.5 \mathrm{mpg}$ in the $11 \%, 19 \%$, and $23 \%$ lightweighting options, respectively. The simulation results fall within the range of other studies (Wohlecker et al. 2007; Montalbo et al. 2008). We observe from the simulation result that the secondary weight reduction effect increases with higher LW. The fuel economy difference between secondary LW and primary LW is 0.1 to $0.3 \mathrm{mpg}$ for the $6 \% \mathrm{LW}$ option versus 1.1 to $1.8 \mathrm{mpg}$ for the $23 \% \mathrm{LW}$ option.

\section{Life Cycle GHG Emissions and EoL Materials Recovery}

We used previous LCA studies of aluminum and steel production (Ecobalance and NPPC 1997; Das 2000a, 2000b; IAI 2000; Choate and Green 2003; Schifo and Radia 2004; US EPA 2004; KNCPC 2005; IPCC 2007; NREL 2007; WSA 2008) to estimate added upstream emissions associated with LW. These emissions factors are provided in table 3 . Here we consider the primary and secondary production of steel and aluminum, as well as the manufacturing processes required to produce finished LW components. Table 3 also provides emission factors for cast and wrought alloys of aluminum (IAI 2000; IPCC 2007). For both primary aluminum and HSS, we consider a "typical" emission factor to be the U.S. average emission factor (IAI 2000; Schifo and Radia 2004). For a high emission factor estimate, we used the emissions factors from countries that use GHG-intensive energy and 


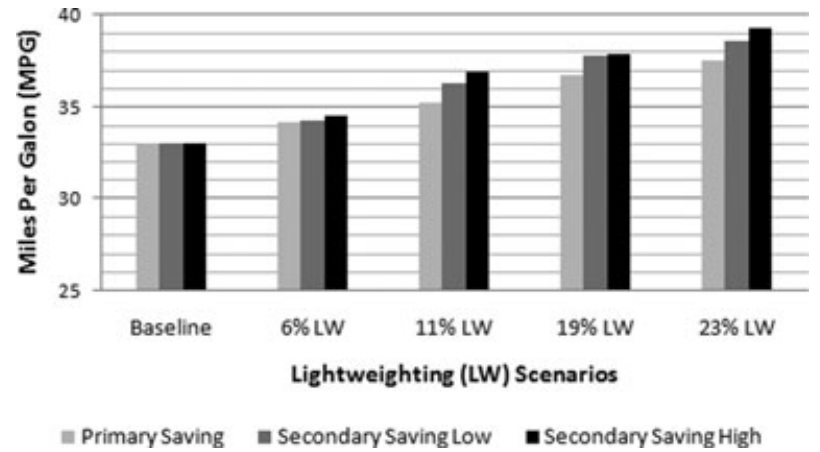

Figure 2 Fuel economy for each lightweighting (LW) scenario developed via AVL CRUISE. Secondary LW scenarios are applied in a range of $3.0 \%$ to $8.2 \%$, with the resultant impact on fuel economy as shown in the figure. material production facilities. For aluminum, we consider the emission factor "high" estimate to be the average emission factor for aluminum made in China (IAI 2000). For steel, we assume the high estimate of the steel emission factor to be the one referenced by the Fourth IPCC Assessment Report on Climate Change (IPCC 2007). ${ }^{9}$

The aluminum manufacturing processes considered include casting, extruding, and rolling. For aluminum casting, an average of the lost foam, die, and sand casting processes is calculated as 5.5 kilograms of carbon dioxide equivalent per kilogram ( $\mathrm{kg} \mathrm{CO}$-eq/kg; Schifo and Radia 2004). Aluminum rolling and extruding are assumed to have emission factors of $0.26 \mathrm{~kg}$ $\mathrm{CO}_{2}$-eq $/ \mathrm{kg}$ and $0.34 \mathrm{~kg} \mathrm{CO}$-eq $/ \mathrm{kg}$, respectively (Choate and Green 2003).

For a sensitivity analysis on VMT, we considered a vehicle lifetime from 11 years (Choate and Green 2003) to 16 years (Das 2000a, 2000b). This yielded a range of VMT from 120,000 miles to 181,195 miles. Given the VMT and the modeled fuel economy of each vehicle, the total usephase gasoline consumption was calculated. Life cycle carbon dioxide $\left(\mathrm{CO}_{2}\right)$ emissions from gasoline consumption for the vehicles were calculated with an emission factor of $10.4 \mathrm{~kg} \mathrm{CO}_{2}$ /gallon gasoline. This includes emissions from both the combustion of gasoline $\left(8.79 \mathrm{~kg} \mathrm{CO}_{2}\right.$ /gallon [US EPA 2004]) and the production and delivery of gasoline (1.58 kg CO 2 -eq/gallon [NREL 2007]). The vehicle use-phase gasoline consumption and GHG emissions are summarized in table 4.

A separate model was created for treating EoL vehicle (ELV) emissions and reuse of materials. We use the vehicle EoL rate and vehicle scrappage rate model from work by Schmoyer (2001). Steel and aluminum shredding efficiencies are estimated at $90 \%$ and $70 \%$, respectively. We considered both "closed-loop recycling" (where all the iron, steel, and aluminum materials are sorted by alloy and the alloys are recycled without

Table 3 Greenhouse gas emission factors for steel and aluminum production

\begin{tabular}{lll}
\hline Extent of emission & \multicolumn{1}{c}{ Metals } & \multicolumn{1}{c}{ Emission factor } \\
\hline Baseline estimate & Primary steel & $2.2 \mathrm{~kg} \mathrm{CO}_{2}$-eq $/ \mathrm{kg}$ steel (Schifo and Radia 2004) \\
& Primary high-strength steel & $2.8 \mathrm{~kg} \mathrm{CO}$-eq $/ \mathrm{kg}$ steel (KNCPC 2005) \\
& Secondary steel & $0.7 \mathrm{~kg} \mathrm{CO}_{2}$-eq $/ \mathrm{kg}$ steel (WSA 2008) \\
& Primary cast Al & $9.72 \mathrm{~kg} \mathrm{CO}$-eq $/ \mathrm{kg} \mathrm{Al}$ (IAI 2000) \\
& Primary wrought Al & $9.45 \mathrm{~kg} \mathrm{CO}_{2}$-eq $/ \mathrm{kg} \mathrm{Al}$ (IAI 2000) \\
& Secondary cast Al & $1.18 \mathrm{~kg} \mathrm{CO}$-eq $/ \mathrm{kg} \mathrm{Al} \mathrm{(IAI} \mathrm{2000)}$ \\
& Secondary wrought Al & $0.90 \mathrm{~kg} \mathrm{CO}_{2}$-eq $/ \mathrm{kg} \mathrm{Al} \mathrm{(IAI} \mathrm{2000)}$ \\
High estimate & Primary steel & $3.8 \mathrm{~kg} \mathrm{CO}$-eq $/ \mathrm{kg}$ steel (IPCC et al. 2007) \\
& Primary cast Al & $26.6 \mathrm{~kg} \mathrm{CO}_{2}$-eq $/ \mathrm{kg} \mathrm{Al} \mathrm{(IAI} \mathrm{2000)}$ \\
\hline
\end{tabular}

Note: $\mathrm{CO}_{2}$-eq.: Carbon dioxide equivalent is a measure for describing the climate-forcing strength of a quantity of greenhouse gases using the functionally equivalent amount of carbon dioxide $\left(\mathrm{CO}_{2}\right)$ as the reference; $\mathrm{Al}=$ aluminum. 
Table 4 Vehicle use-phase gasoline consumption and greenhouse gas (GHG) emissions for low (I20,000 miles) and high (I8I,195 miles) vehicle miles traveled (VMT; $\mathrm{kg} \mathrm{CO}_{2}$-eq)

\begin{tabular}{|c|c|c|c|c|}
\hline \multirow[b]{2}{*}{ Lightweighting options } & \multicolumn{2}{|c|}{$\begin{array}{l}\text { Lifetime gasoline } \\
\text { consumption (gallons) }\end{array}$} & \multicolumn{2}{|c|}{$\begin{array}{l}\text { Use-phase total emissions } \\
\qquad\left(\mathrm{kg} \mathrm{CO} \mathrm{CO}_{2} \text {-eq) }\right.\end{array}$} \\
\hline & Low & High & Low & High \\
\hline Baseline vehicle & 3,635 & 5,489 & 38,248 & 57,753 \\
\hline 6\% LW & 3,505 & 5,292 & 35,547 & 54,178 \\
\hline $11 \% \mathrm{LW}$ & 3,411 & 5,150 & 32,548 & 49,145 \\
\hline $19 \%$ LW & 3,267 & 4,934 & 29,500 & 44,544 \\
\hline $23 \% \mathrm{LW}$ & 3,200 & 4,831 & 27,945 & 42,197 \\
\hline
\end{tabular}

Note: $\mathrm{kg} \mathrm{CO}_{2}$-eq = kilograms carbon dioxide equivalent; $\mathrm{LW}=$ lightweighting.

downcycling for use in new vehicles) and conventional recycling as practiced today. The allocation approach used is a slight modification of the approach of Werner and Richter (2000). We assumed that $93 \%$ of all LW metals are collected at the end of life (IISI 2006) and that $95 \%$ and $89 \%$ of the steel and aluminum, respectively, are recovered after disassembling, shredding, separating, and sorting, on the basis of research by Zapp and colleagues (2003). Recovery of metal scrap after melting was assumed to be $95 \%$ for steel and $91 \%$ for aluminum. Wrought and cast aluminum separating efficiency was estimated at 95\% (Das 1999; Nathani and Arnsberg 2002).

GHG emissions were also calculated for the ELV processes of disassembly, shredding, and nonferrous separation on the basis of energy consumption data and an assumed $\mathrm{CO}_{2}$ emission per unit energy delivered (assumed totally as electricity; Schifo and Radia 2004). Transportation emissions were also calculated for the movement of material between process stages, as well as for the transport of automotive shredder residue (ASR) to landfill disposal (Schifo and Radia 2004). The transportation distance between EoL activities was assumed to be 100 miles, consistent with analysis by Keoleian (1997). The transportation distance between the EoL activities and landfill was assumed to be 200 miles (Keoleian 1997). The transportation mode was assumed to be a single-unit diesel truck with emission factor obtained from the U.S. life cycle inventory (LCI) database (NREL 2007). Table 5 summarizes the EoL GHG emissions assumed in the analysis. The values assume that all energy values are electric- ity, with electricity having life cycle GHG emissions equal to the average U.S. grid as per the U.S. LCI database (NREL 2007).

\section{Results}

\section{Life Cycle GHG Emissions}

Table 6 summarizes the vehicle GHG emissions by life cycle phase. As expected, the use phase dominates the total GHG emissions for each vehicle ( $87 \%$ to $95 \%$ ). By percentage of the total life cycle emissions, use-phase emissions decrease in percentage, as expected with increased LW, whereas material production and manufacturing emissions increase in percentage due to the additional use of higher GHG-intensity metals relative to the mild steels being replaced. Even with the highest emission factors applied for these materials, the GHG emissions for the production phase are only increased by about 15\%

Table 5 Greenhouse gas (GHG) emissions from end-of-life (EoL) process $\left(\mathrm{kg} \mathrm{CO}_{2}\right.$-eq $\left.{ }^{10}\right)$

\begin{tabular}{|c|c|c|c|}
\hline LW option & $\begin{array}{c}\text { ELV } \\
\text { processes }\end{array}$ & Transport & $\begin{array}{c}\text { Total } \\
\left(\mathrm{kg} \mathrm{CO} \mathrm{CO}_{2} \text {-eq) }\right.\end{array}$ \\
\hline Baseline vehicle & 47 & 100 & 147 \\
\hline 6\% LW & 44 & 94 & 138 \\
\hline $11 \%$ LW & 39 & 83 & 122 \\
\hline 19\% LW & 35 & 73 & 108 \\
\hline $23 \%$ LW & 32 & 68 & 100 \\
\hline
\end{tabular}

Note: $\mathrm{kg} \mathrm{CO}_{2}$-eq = kilograms carbon dioxide equivalent; $\mathrm{LW}=$ lightweighting; ELV = end-of-life vehicle. 
Table 6 Life cycle greenhouse gas (GHG) emissions for each lightweighting (LW) scenario (kg CO 2 -eq)

\begin{tabular}{|c|c|c|c|c|c|c|c|c|}
\hline \multirow[b]{3}{*}{ LW options } & \multicolumn{3}{|c|}{ Production } & & & \multirow[b]{3}{*}{ EoL } & & \\
\hline & \multirow{2}{*}{$\begin{array}{l}\text { Low } \\
\text { emission } \\
\text { factors }\end{array}$} & \multirow{2}{*}{$\begin{array}{c}\text { Mid } \\
\text { emission } \\
\text { factors }\end{array}$} & \multirow{2}{*}{$\begin{array}{l}\text { High } \\
\text { emission } \\
\text { factors }\end{array}$} & \multicolumn{2}{|c|}{ Use } & & \multicolumn{2}{|c|}{ Total } \\
\hline & & & & Low & $\overline{\text { High }}$ & & Low & $\overline{\text { High }}$ \\
\hline Baseline vehicle & 1,670 & 3,590 & 4,100 & 38,248 & 57,753 & 147 & 40,065 & 62,000 \\
\hline 6\% LW HSS & 1,620 & 3,630 & 4,200 & 35,547 & 54,178 & 138 & 37,305 & 58,516 \\
\hline $6 \% \mathrm{LW} \mathrm{AL}$ & 1,640 & 3,750 & 4,350 & 35,547 & 54,178 & 122 & 37,325 & 58,666 \\
\hline $11 \% \mathrm{LW} \mathrm{AL}$ & 1,613 & 4,320 & 5,090 & 32,548 & 49,145 & 108 & 34,362 & 54,483 \\
\hline 19\% LW HSS & 1,563 & 3,700 & 4,820 & 29,500 & 44,544 & 100 & 31,171 & 49,472 \\
\hline 23\% LW AL & 1,566 & 5,720 & 6,540 & 27,945 & 42,197 & 147 & 29,611 & 48,837 \\
\hline
\end{tabular}

Note: $\mathrm{EoL}=$ end of life; HSS = high-strength steel; $\mathrm{AL}=$ aluminum.

above the baseline vehicle production emissions. Conversely, if (entirely) secondary materials were used for LW, the GHG emissions of production would be decreased by $20 \%$ to $47 \%$ relative to the baseline vehicle production scenario (given the production emission factor lower bound values from table 6). Therefore, the LW material GHG emission factors and the use of secondary materials play the key roles in determining the GHG emissions of the production phase. For broad ranges of assumptions on these emissions, $\mathrm{LW}$ is an effective approach to achieve a total life cycle GHG reduction from the modeled baseline vehicle. It should also be noted, however, that there are minimum travel threshold distances (less than 9,479 miles, less than 67,150 miles) for HSS ( $6 \%$ LW, 19\% LW) and (less than 54,590 miles, less than 106,270 miles) for aluminum (6\% LW, $23 \%$ LW) for which LW does not pay back.

\section{GHG Emissions Payback Time}

To compare the life cycle emissions between the baseline vehicle and LW versions of that vehicle, we constructed a simple normalization model that assumes one new vehicle is produced each year. The production emissions include upstream materials production and increased manufacturing emissions associated with incorporating lightweight materials into the baseline vehicle. We then assume every vehicle is sold, such that there is one LW vehicle on the road in Year 1, two vehicles on the road in Year 2 , and so on. The approach therefore considers emissions from production as well as savings from the fleet of vehicles produced in previous years. VMT/vehicle/year depends on vehicle age as described in Supporting Information part D, available on the Web. The results provided in figures 3-5 consider the emissions associated with the LW vehicles compared with the baseline vehicle, such that the baseline vehicle life cycle emissions are always represented by the value zero on the $y$-axis for all years.

Three LW comparisons are presented. These are as follows:

- comparison of $6 \% \mathrm{LW}$ with aluminum and HSS (figure 3)

- comparison among 6\%, $11 \%$, and $23 \%$ aluminum LWs (figure 4)

- comparison between 19\% HSS and 23\% aluminum LW (figure 5).

Regarding the comparison between 6\% LW with aluminum and HSS in figure 3, a clear impact arises from the material production stage. We can observe that $6 \%$ LW with HSS is less sensitive to the material production emission factors than $6 \%$ aluminum LW. Conversely, it is evident that $6 \%$ aluminum LW could be more beneficial than $6 \%$ HSS if the aluminum vehicle could be made entirely from secondary aluminum; however, if entirely secondary HSS were used, then the secondary HSS approach would be more beneficial than the secondary $\mathrm{Al}$ approach, because the GHG intensity for secondary aluminum is higher than for secondary steel (see table 3). We also observe that $6 \%$ aluminum $\mathrm{LW}$, with its baseline emission factor, has a higher 


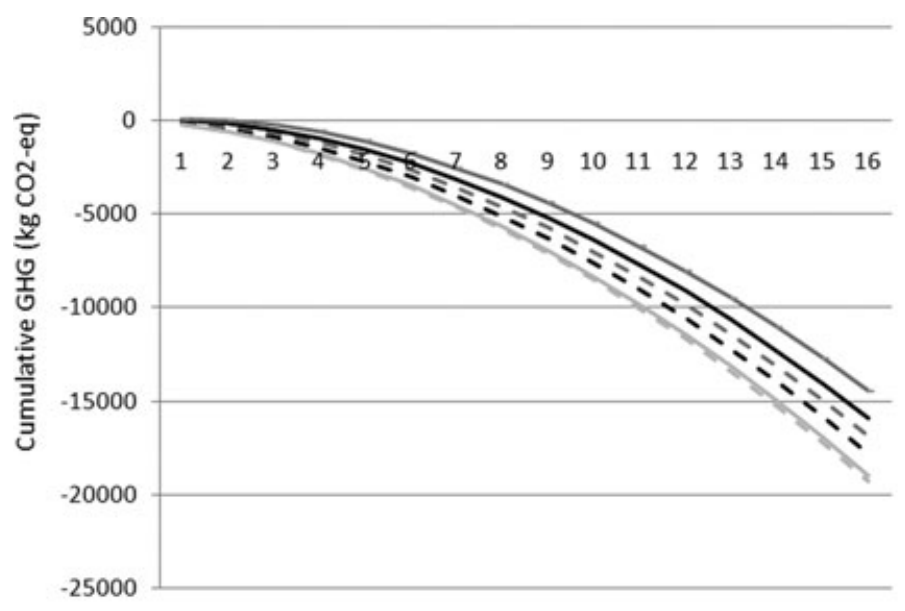

Vehicle Life Time (Year)
- - HSS 6\% LW baseline emission factor

- - HSS 6\% LW high emission factor

- - HSS 6\% LW secondary material

AL $6 \%$ LW baseline emission factor

-AL $6 \%$ LW high emission factor

- AL $6 \%$ LW secondary material

HSS: High Strength Steel

AL: Aluminum

LW: Lightweighting

Figure 3 Cumulative greenhouse gas (GHG) emissions for 6\% high-strength steel (HSS) versus 6\% aluminum (Al) lightweighting (LW). $\mathrm{kg} \mathrm{CO}$-eq = kilograms carbon dioxide equivalent.

GHG emission impact than 6\% HSS LW, with its high emission factor. Overall, the GHG emission payback times vary between 1 and 4 years for $6 \%$ HSS LW and between 4 and 6 years for $6 \%$ aluminum LW. Therefore, for the example vehicle used in this article, HSS has better performance for saving GHG than aluminum at a low percentage of LW.
Next we compare the life cycle GHG emissions of the $6 \%, 11 \%$, and $23 \%$ aluminum LW vehicles (with high and nominal emission factors) relative to the baseline vehicle (figure 4). The GHG emission payback times are 4 to 6 years for $6 \% \mathrm{LW}, 2$ to 9 years for $11 \% \mathrm{LW}$, and 4 to 10 years for $23 \% \mathrm{LW}$. Here we observe that the life cycle GHG saving of $23 \% \mathrm{LW}$ is 24,000

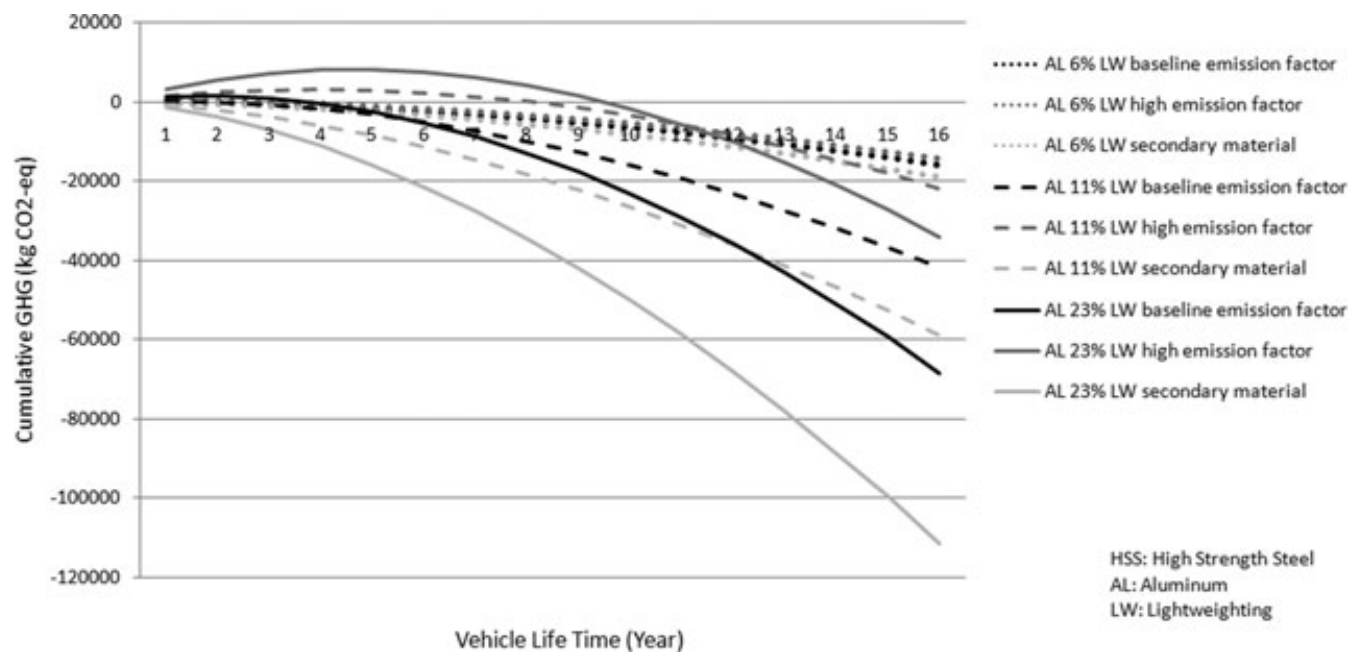

Figure 4 Cumulative greenhouse gas (GHG) emissions for 6\%, I I\%, and 23\% aluminum (Al) lightweighting (LW). $\mathrm{kg} \mathrm{CO}$-eq = kilograms carbon dioxide equivalent. 


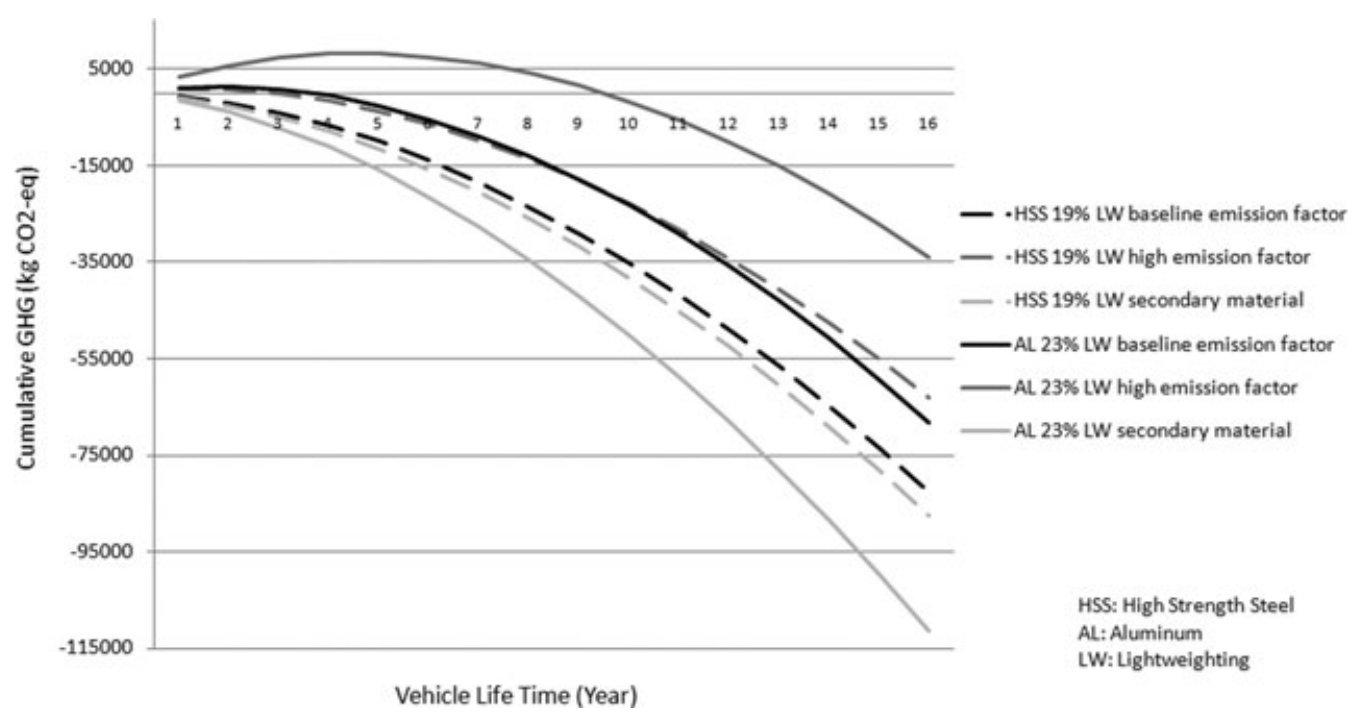

Figure 5 Cumulative greenhouse gas (GHG) emissions for 19\% high-strength steel (HSS) and 23\% aluminum (Al) lightweighting (LW). $\mathrm{kg} \mathrm{CO}$-eq = kilograms carbon dioxide equivalent.

to $56,000 \mathrm{~kg} \mathrm{CO}$-eq per vehicle, which is $230 \%$ to $440 \%$ greater than the GHG savings of $6 \%$ $\mathrm{LW}$. It is observed that $23 \%$ aluminum $\mathrm{LW}$ is the most beneficial option even though it also requires the largest GHG investment in the production phase. Given that the $11 \% \mathrm{LW}$ vehicle is $110 \%$ to $290 \%$ greater than the GHG savings of $6 \% \mathrm{LW}$, we see that the higher end of the GHG savings is roughly proportional to the percentage mass reduction. For the $23 \% \mathrm{LW}$ vehicle, the effect of LW by secondary aluminum over primary aluminum is quite significant $(89,000 \mathrm{~kg}$ $\mathrm{CO}_{2}$-eq).

Figure 5 provides a comparison between 19\% LW with $\mathrm{HSS}$ and $23 \% \mathrm{LW}$ with aluminum. This comparison considers the maximum achieved $\mathrm{LW}$ values for these materials found in the literature. We observe that $19 \%$ HSS LW has significantly lower GHG emissions than 23\% aluminum LW in the production phase. Therefore, the GHG emission payback times are 1 to 3 years for $19 \%$ HSS and 4 to 10 years for $23 \%$ aluminum. 19\% HSS LW has a significant advantage for GHG saving benefits, approximately 15,000 to $29,000 \mathrm{~kg} \mathrm{CO}_{2}$-eq per vehicle relative to the $23 \%$ aluminum $\mathrm{LW}$, although it requires a significant amount of secondary LW achieved through component downsizing, which could be difficult to achieve from the cost perspective and is likely to include some use of aluminum. The only way for $23 \% \mathrm{LW}$ with aluminum to exceed the benefits of $19 \% \mathrm{LW}$ with HSS is if one uses secondary aluminum and acquires the aluminum from stateof-the-art production processes with electricity created from sources with a relatively low GHG footprint. When secondary aluminum is used in the scenarios of this article, the GHG saving benefits for the 23\% aluminum LW over 19\% HSS LW are approximately $20,000 \mathrm{~kg} \mathrm{CO}$-eq.

Payback times were also computed under an assumed production volume increase (instead of a constant production volume as considered in figures 3-5) over time. This considers the case where new materials systems "ramp up" to higher production volumes and has the effect of increasing payback times. It also extends the period of time required for a closed-loop aluminum infrastructure to make up for the total fleet production of aluminum. Under this situation, the payback time for the $11 \% \mathrm{LW}$ with aluminum option is 3 to 11 years, with a $5 \%$ annual production volume increase, whereas the payback time with constant production is 2 to 9 years. With a $5 \%$ annual production volume increase, the 16th-year GHG emission in the production phase reaches two times the GHG emission for the 1st year. 


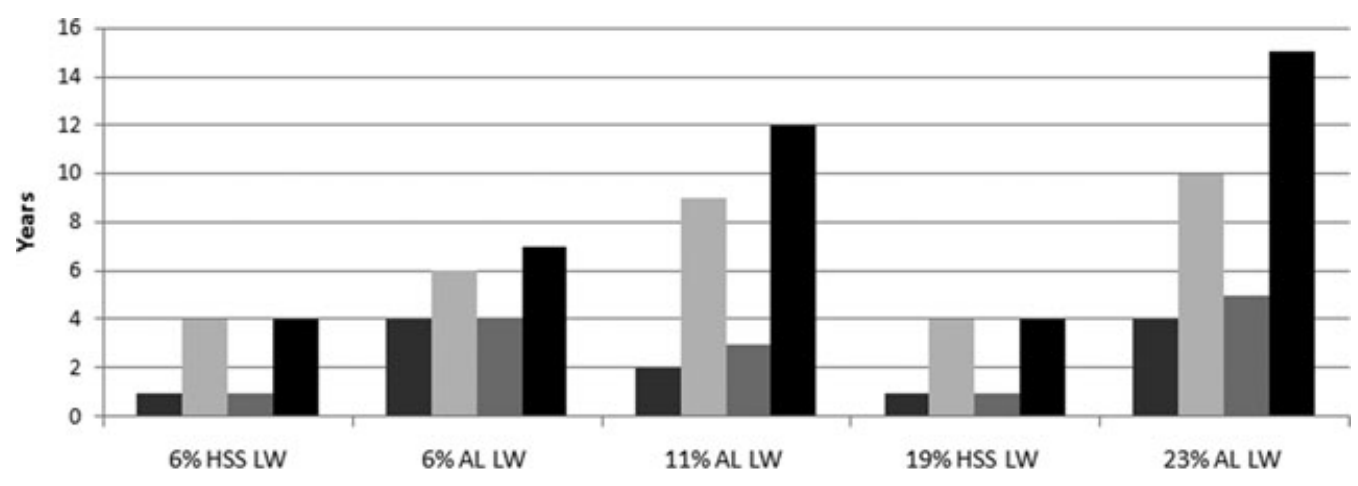

Lightweighting (LW) Scenarios

- Payback time with baseline emission factor

In Payback time with high emission factor

= Payback time with $5 \%$ production volume increase p.a.(baseline emission)

- Payback time with $5 \%$ production volume increase p.a.(high emission)

HSS: High Strength Steel

AL:Aluminum

LW: Lightweighting

Figure 6 Expected payback time for lightweighting (LW) scenarios considering a production volume increase of $5 \%$ per year (for 16 years). p.a. $=$ per annum.

In this case, the GHG savings are reduced by 3,400 to $12,600 \mathrm{~kg} \mathrm{CO}_{2}$-eq relative to the constant production scenario. Figure 6 summarizes the expected payback time of the LW options for a constant production volume and a production volume increase.

\section{GHG Emissions Savings with Recycling}

Since secondary metals emit much less GHG per kilogram for production, we now focus on possible emissions savings associated with establishing a "closed-loop" infrastructure for recovering wrought aluminum from vehicles and recycling it directly into secondary wrought aluminum. This currently does not occur, as all aluminum recovered from vehicles is recycled (downcycled) as cast aluminum. We begin by assuming the ELV scenario used by Schmoyer (2001), in which about $93 \%$ of the vehicles do not survive past 16 years. We then assume that all ELVs are processed in recycling plants.

Figure 7 summarizes the life cycle GHG emissions for the $6 \%, 11 \%$, and $23 \%$ aluminum LW vehicles with and without closed-loop recycling. It can be derived from table 3 that closed-loop recycling should reduce production emissions associated with wrought aluminum by up to 9 times.
This is not achieved, however, because in the early years there is not an appreciable amount of secondary wrought aluminum available to use in new vehicles. Therefore, the benefits grow over time, but the approach is not an effective solution to reduce emissions significantly for time scales less than 1 decade. The benefit naturally takes more than one complete turnover (16 years) due to the need to collect ELVs, the possibility for product leakage outside the recycling infrastructure, and increasing production volumes.

It should be noted that here we assume a truly closed-loop system - which means that only scrapped vehicles produced after the 1st year are available for the secondary wrought aluminum stream. Naturally, other sources for specialized secondary aluminum alloys could emerge, but at the current time this seems unlikely. In this study, we used the vehicle retirement rate and vehicle scrappage rate model from Schmoyer (2001). The vehicle scrappage rate is lower than the vehicle retirement rate due to ELV leakage outside the recycling infrastructure, where a small percentage of retired vehicles are not recycled. The base "recycling" case is modeled with the vehicle scrappage rate. The "recycling high scrappage" case is determined from the vehicle retirement rate and assumes all retired vehicles are collected 


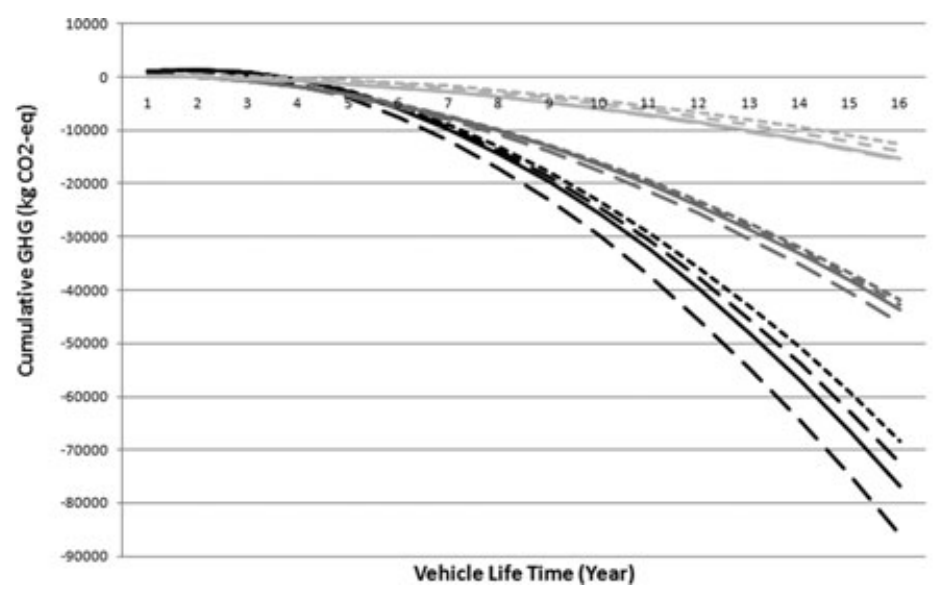

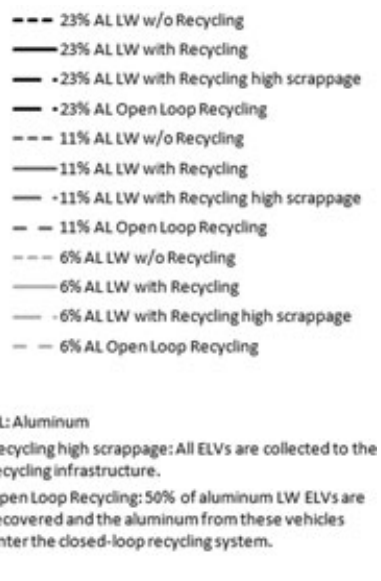

--23\% AL LW w/o Recycling

- 23\% ALOpentoop Reocling

- - 11\% AL L W w/oRecycling

$11 \%$ AL LW wath Recycling

- $-11 \%$ AL LW with Recycling high scrappage

- $11 \%$ AL Open Loop Recycling

- .6\% AL LW with Recycling high scrappage

- 65AL Open loop Recycling

All fivs are collected to the recycling infrastructure.

Open LCop Recycing: $50 \%$ of aluminum LW ElVsare enter the closed-loop re cycling system.

Figure 7 Cumulative greenhouse gas (GHG) emissions achieved by closed-loop aluminum recycling. $\mathrm{kg}$ $\mathrm{CO}_{2}$-eq = kilograms carbon dioxide equivalent; $\mathrm{w} / \mathrm{O}=$ without; $\mathrm{LW}=$ lightweighting; $\mathrm{ELV}=$ end-of-life vehicle.

and recycled. The closed-loop system condition is extreme, so we include one additional scenario whereby $50 \%$ of LW ELVs are processed with open-loop recycling for aluminum.

With the assumption of a $93 \%$ scrappage rate after 16 years of vehicle life after Schmoyer (2001), it would take at least until Year 16 before it is possible to offset $93 \%$ of the primary wrought aluminum with secondary wrought aluminum, given constant production levels of new aluminum-intensive vehicles. By Year 16, closedloop recycling would offset $17,600 \mathrm{~kg} \mathrm{CO}$-eq per vehicle under these assumptions in the $23 \%$ LW case while only off-setting $3,000 \mathrm{~kg} \mathrm{CO}_{2}$-eq per vehicle in the $6 \% \mathrm{LW}$ case (this is less than 1 year of driving that vehicle). The open-loop recycling for the $23 \% \mathrm{LW}$ case has about $4,000 \mathrm{~kg}$ $\mathrm{CO}_{2}$-eq offset. In comparison, the added GHG value of closed-loop HSS recycling is relatively low, because the GHG saving benefits through HSS recycling are significantly smaller than the case of aluminum. A closed loop recycling system saves less than $4,800 \mathrm{~kg} \mathrm{CO}_{2}$-eq per vehicle for the 19\% LW scenario with HSS. The reason for the smaller GHG saving benefits with closedloop HSS recycling is that most steel is already recycled at the current time, and HSS has no additional GHG saving effect relative to mild steel by recycling.
We should note while contextualizing these results that a large penetration of aluminumintensive vehicles in the market would be expected to have broader impact on primary and secondary aluminum production and use that is not captured in our modeling. In addition, mixed aluminum and HSS strategies are feasible. For instance, a $14.7 \% \mathrm{LW}$ vehicle is achievable with $387.5 \mathrm{~kg}$ of BIW by HSS and $179.5 \mathrm{~kg}$ of aluminum internal components. The life cycle GHG emission is estimated at 34,530 to $54,813 \mathrm{~kg} \mathrm{CO}_{2}$ eq (production phase GHG is estimated at 1,409 to $4,691 \mathrm{~kg} \mathrm{CO}_{2}$-eq), which is roughly similar to the $19 \%$ aluminum LW vehicle. This suggests that mixed aluminum and HSS material strategies can be more efficient from a perspective of GHG reduction per mass of LW achieved than the use of either aluminum or HSS alone.

\section{Summary and Conclusions}

In this article, we have developed a detailed life cycle and materials model to quantify the GHG costs and benefits arising from lightweighting with HSS and aluminum. Distinct from previous research that has studied the maximum achievable vehicle lightweighting using aluminum and HSS (Ng et al. 1999; Das et al. 1997; Das 2000a, 2000b; IAI 2000; Austin et al. 
2002; Obenchain et al. 2002; Wallentowitz et al. 2006), this study has investigated material tradeoffs in the context of a specific vehicle analyzed with a detailed engineering model. Modeling a specific vehicle allows the development of a complete picture of the magnitude of GHG trade-offs between aluminum and HSS absent the assumption of a closed-loop aluminum infrastructure, which is decades away.

The article presents an analysis of how important production versus use-phase trade-offs are in the context of meeting societal goals for reducing GHG emissions from the automotive sector in the short run. More specifically, we developed a model to estimate the life cycle emissions reductions associated with different levels of LW using aluminum versus HSS. We also assessed the impact of a closed-loop wrought material recycling system, factoring in where the primary material was produced. The analysis further considers whether the GHG payback periods are significant relative to the time scales over which emissions reductions are needed from the passenger vehicle industry. Key findings from the study are as follows:

1. It is possible to develop realistic LW options using both HSS and aluminum for a specific compact-sized vehicle. Considering a range of emissions factors for HSS and aluminum, we found for HSS in the range of $6 \%$ to $19 \% \mathrm{LW}$ that there is a $1-$ 4-year GHG payback to recover the added production emissions. Periods of 4-6 years, 2-9 years, and 4-10 years were observed for the $6 \%, 11 \%$, and $23 \% \mathrm{LW}$ options for aluminum, respectively. We observed that payback periods for HSS are generally shorter than aluminum.

2. GHG savings for aluminum LW vary strongly with GHG emission factors and whether secondary aluminum can be used. HSS is less sensitive to these parameters. Therefore, especially for aluminum, production techniques with lower emission factors and electricity generated by nuclear or renewable energy can have a major impact on reducing production emissions. Secondary aluminum can dramatically reduce payback periods and would have a greater impact than cleaner aluminum production sources. For instance, we estimate only a 1-2-year payback for secondary aluminum $L W$ vehicles, even with a $5 \%$ vehicle production volume increase.

3. Although payback times can be shortened for aluminum-intensive vehicles by closedloop recycling of wrought aluminum (i.e., the use of secondary wrought aluminum), this practice does not currently occur. Therefore, over a 15-year time horizon, this is unlikely to make much difference due to a lack of secondary wrought aluminum in the pipeline and the possibility of a growth in the demand for LW vehicles. Over the longer term (approaching 2 decades), as lightweight materials become available for recycling and are incorporated into new vehicles, closed-loop recycling can significantly reduce the impacts of aluminum-intensive vehicles.

4. If we consider only GHG savings, it is advantageous to emphasize HSS LW in the BIW until technology for current secondary sources of aluminum can be used to produce wrought automotive-grade aluminum or until carbon markets or similar developments take effect and can lead to the reduction in GHG intensity of existing primary aluminum sources. Beyond the BIW and maximum achievable LW using HSS, a combination of aluminum and HSS can be considered to maximize LW and GHG emissions reductions together in the most cost-effective manner.

Naturally, the actual implementation of GHG reduction strategies is largely dictated by costs. This is the subject of a companion article (Kim et al. 2010). In that article, the GHG reductions from LW reported here are combined with a comprehensive cost analysis of each aluminum and HSS LW strategy to evaluate their costeffectiveness in terms of dollars per metric ton of carbon dioxide equivalent.

\section{Acknowledgment}

This research was supported by the Alcoa Foundation's Conservation and Sustainability 
Fellowship Program and the National Science Foundation MUSES (National Science Foundation Materials Use: Science, Engineering and Society) grant (CMMI 0628162). One of the authors was partially funded through the Alcoa Foundation's Conservation and Sustainability postdoctoral fellowship program, which is a separate entity from Alcoa. The project was initiated independently of Alcoa and the steel industry as part of the NSF MUSES grant. Any opinions, findings, and conclusions or recommendations expressed in this material are ours and do not necessarily reflect the views of the National Science Foundation or other sources of funding. We thank Ford Motor Company, the International Iron and Steel Institute, and Alcoa Inc. for their helpful input and critical comments, which led to a comprehensive analysis.

\section{Notes}

1. Mild steel contains $0.16 \%$ to $0.29 \%$ carbon and is the most commonly used form of steel due to its low price and adequate material properties for many applications (Babylon 2009).

2. One kilogram $(\mathrm{kg}, \mathrm{SI}) \approx 2.204$ pounds $(\mathrm{lb})$.

3. "Compact-class" or "Compact-sized" vehicle is a classification of cars that are larger than subcompact but smaller than mid-sized cars. Common engines are 1.5 to 2.4 liters. The Ford Focus and Honda Civic are in this class.

4. VMT is a unit that measures vehicle travel regardless of the number of persons in the vehicle (Babylon 2009).

5. "EoL" is a term used with respect to terminating the sale or support of products and services. In industrial ecology, it refers to the postuse stage of the product life cycle.

6. A light metal is a metal of low atomic weight. Lithium, sodium magnesium, and aluminum are included (Babylon 2009).

7. The material prices were taken in July 2008.

8. Mpg is a unit of measurement that measures how many miles a vehicle can travel on 1 gallon of fuel. One mile $(\mathrm{mi}) \approx 1.61$ kilometers $(\mathrm{km})$; one gallon $($ gal $) \approx 3.79$ liters $(1)$. Thus, $1 \mathrm{mpg} \approx 0.42 \mathrm{~km} / 1$.

9. After this article was originally submitted for publication, the steel and aluminum industries reported new upper ranges for primary steel and secondary aluminum GHG emission factors. These are significantly smaller than values in the literature: with values of $2.7 \mathrm{~kg} \mathrm{CO}$-eq $/ \mathrm{kg}$ for primary steel (WSA 2008) and $0.5 \mathrm{~kg} \mathrm{CO}$-eq $/ \mathrm{kg}$ for secondary aluminum (EAA 2008). We therefore include an additional life cycle GHG emissions assessment using these data in Table S-1 in the Supporting Information on the Web. Subsequent to the publishing of those industry data, World Auto Steel communicated its understanding that the difference in the industry average carbon intensity between HSS and primary steel is not expected to exceed 5\%. Although these revised industry values are not reported in the main body of the article, they do not change the main findings of the research discussed in the Summary and Conclusions section.

\section{References}

Austin, T. C., R. G. Dulla, and T. R. Carlson. 1999. Alternative and future technologies for reducing greenhouse gas emissions from road vehicles. Technical report. Sacramento, CA: Sierra Research Inc.

Babylon. 2009. Babylon's free dictionary. http:// dictionary.babylon.com/. Accessed 15 July 2009.

Choate, W. T. and J. A. S. Green. 2003. U.S. energy requirements for aluminum production: Historical perspective, theoretical limits and new opportunities. Washington, DC: U.S. Department of Energy.

Das, S. 1999. Supporting infrastructure and acceptability issues for materials used in new generation vehicles. Oak Ridge, TN: Oak Ridge National Laboratory.

Das, S. 2000a. The life cycle impacts of aluminum body in white automotive material. JOM: Journal of the Minerals, Metals and Materials Society 52(8): 4144.

Das, S. 2000b. Supporting infrastructure and acceptability issues associated with two new generation vehicles: P2000 and ESX2. Oak Ridge, TN: Oak Ridge National Laboratory.

Das, S., T. R. Curlee, and S. M. Chhexnayder. 1997. Materials used in new generation vehicles: Supplies, shifts and supporting infrastructure. Oak Ridge, TN: Oak Ridge National Laboratory.

Dieffenbach, J. R. and A. E. Mascarin. 1993. Bodyin-white material systems: A life-cycle cost comparison. JOM: Journal of the Minerals, Metals and Materials Society. 19-37. Available from: www. eaa.net/upl/4/default/doc/EAA_Environmental_ profile_report_May08.pdf. Accessed October 2010.

EAA (European Aluminium Association). 2008. Environmental profile report for the European aluminium industry: Life cycle inventory data for aluminium 
production and transformation processes in Europe. Brussels, Belgium: European Aluminium Association.

Ecobalance and NPPC (Ecobalance and National Pollution Prevention Center). 1997. Life cycle inventory analysis of a generic vehicle. Results report. Ann Arbor, MI: U.S. Advanced Materials Partnership, Life Cycle Assessment Special Topics Group, Automobile Industry Sub-Group.

Gaines, L. and R. Cuenca. 2002. Operation of an aluminum-intensive vehicle: Report on a sixyear project. Technical Paper No. 2002-01-2066. Warrendale, PA: Society of Automotive Engineers (SAE).

Geyer, R. 2008. Parametric assessment of climate change impacts of automotive material substitution. Environmental Science and Technology 42: 6973-6979.

Han, H. N. 1996. The environmental impact of steel and aluminum body-in-whites. JOM: Journal of the Minerals, Metals and Materials Society 48(2): 33-39.

Han, H. N. and J. P. Clark. 1995. Lifetime costing of the body-in-whites: Steel vs. aluminum. JOM Journal of the Minerals, Metals and Materials Society 47(5): 22-28.

Henn, R. and J. Leyers. 2006. Communication module mass reduction. Forschungsgesellschaft Kraftfahrwesen (fka) Report 56690. Forschungsgesellschaft Kraftfahrwesen mbH Aachen. www. worldautosteel.org/.../Fka_Report_6rh0098_ MassReduction_Nov2006-Final.pdf. Accessed August 2008.

IAI (International Aluminum Institute). 2000. Life cycle inventory of the worldwide aluminum industry with regard to energy consumption and emissions of greenhouse gases, Paper 1-automotive. www. world-aluminium.org/iai/publications/ documents/full_report.pdf.

IISI (International Iron and Steel Institute). 2006. Application of the IISI LCI data to recycling scenarios. www.eurofer.org/contact/docs/ RecyclMethodology.pdf. Accessed 25 September 2006. Accessed August 2008.

IPCC (Intergovernmental Panel on Climate Change). 2007. Climate change 2007: Intergovernmental panel on climate change. IPCC fourth assessment report. Cambridge, UK: Cambridge University Press.

Kelkar, A., R. Roth and J. P. Clark. 2001. Automotive bodies: Can aluminum be an economical alternative to steel? JOM: Journal of the Minerals, Metals and Materials Society 28-32.

Keoleian, G. 1997. Industrial ecology of the automobile:
A life cycle perspective. Warrendale, PA: Society of Automotive Engineers.

Kim, H.-J., S. J. Skerlos, and G. A. Keolian. 2010. Economic assessment of greenhouse gas emissions reduction by vehicle lightweighting using aluminum and high-strength steel. Journal of Industrial Ecology. DOI: 10.1111/j.1530. 9290.2010.00288.x

KNCPC (Korean National Cleaner Production Center). 2005. Korean National Life Cycle Inventory Database. www.kncpc.re.kr/lci/. Accessed August 2008.

Montalbo, T., T.M. Lee, R. Roth, and R. Kirchain. 2008. Modeling costs and fuel economy benefits of lightweighting vehicle closure panels. Paper presented at the SAE 2008 World Congress, Detroit, MI, April 14-17.

Nathani C. and W. Arnsberg. 2002. Materailfluß spezifischer Abfallarten und Abfallkennziffern bedeutender Bereiche-Endbericht Teil I [Materials flow of special waste and waste characterization-Final Report Part I]. Research report. Stuttgart: Fraunhofer Institut für Systemtechnik und Innovationsforschung (ISI).

Neumann, K.-H. and K.-P. Schindler. 2002. Zukünftige Fahrzeugantriebe. [Vehicle powertrain for the future.] In Innovative Fahrzeugantriebe, Presentations 1998-2002 [CD-ROM], edited by VDIGesellschaft Fahrzeug- und Verkehrstechnik. Düsseldorf, Germany: VDI-Verlag.

Ng, G. K., J. C. Miller, and M. B. Tessieri. 1999. Aluminum usage in the PNGV and its impact on the recycling infrastructure. In SAE International Congress and Exposition, Vol. 108. Detroit, MI: Society of Automotive Engineers.

NREL (National Renewable Energy Laboratory). 2007. U.S. Life Cycle Inventory Database: Fuels and energy precombustion. www.nrel.gov/ lci/database/default.asp. Accessed July 2007.

Obenchain, W. A. et al. 2002. ULSABadvanced vehicle concepts (ULSAB-AVC). www.worldautosteel.org/Projects/ULSAB-AVC/ Programme-Detail.aspx. Accessed January 2009.

Opbroek, E. 2007. Personal communication with E. Opbroek, Director of WorldAutoSteel, World Steel Association, Middletown, OH, USA, 19 October 2007.

Scamans, G. 2005. Aluminium structured vehicles: Myths and realities. Paper presented at the Light Metal Surface Science Annual Conference, Trondheim, Norway, 15-16 June 2005.

Schifo, J. F. and J. T. Radia. 2004. Theoretical/best practice energy use. In Metalcasting operations. www1.eere.energy.gov/industry/metalcasting/pdfs 
/doebestpractice_052804.pdf. Accessed December 2007.

Schmoyer, R. 2001. Unpublished study on scrappage rate. Oak Ridge, TN: Oak Ridge National Laboratory.

Tessieri, M. B. and G. K. Ng. 1995. Forecast of aluminum usage in the automotive market and subsequent impact on the recycling infrastructure. In Third International Symposium on Recycling of Metals and Engineered Materials. Warrendale, PA: TMS, Minerals, Metals and Materials Society/AIME (USA).

US EPA (U.S. Environmental Protection Agency). 2004. Climate leaders greenhouse gas inventory protocol core module guidance: Direct emissions from mobile combustion sources. www.epa.gov/ stateply/docs/mobilesourceguidance.pdf. Accessed July 2007.

Wallenotowitz, H., K. H. von Zengen, T. Parr, R. Wohlecker, and D. Wynands. 2002. Lightweight potential of an aluminium intensive vehicle. Final report No.24020. Aachen, Germany: Forschungsgesellschaft Kraftfahrwesen mbH Aachen.

Werner, F. and K. Richter. 2000. Economic allocation in LCA: A case study about aluminium window frames. International Journal of Life Cycle Assessment 5(2): 79-83.

Wohlecker, R., M. Johannaber, and M. Espig. 2007. Determination of weight elasticity of fuel economy for ICE, hybrid and fuel cell vehicles. Paper No. 2007. 01-0343. Warrendale, PA: Society of Automobile Engineers (SAE).

WSA (World Steel Association). 2008. Climate change and greenhouse gas emissions in the steel industry. www.worldautosteel.org/WhySteel/ GHGEmissions.aspx. Accessed November 2008.

Zapp, P., W. Kuckshinrichs, and G. Rombach. 2003. Long term supply of aluminium to the European automotive industry. In Proceedings of European Metallurgical Conference EMC 2003 1: 339 354.

\section{About the Authors}

Hyung-Ju Kim is a postdoctoral research fellow in the Department of Mechanical Engineering at the University of Michigan in Ann Arbor, Michigan, USA. Colin McMillan is a dual degree student in the School of Natural Resources and Environment (Ph.D. candidate) and the Department of Economics (master's degree in applied economics) at the University of Michigan. Dr. Gregory Keoleian is a professor at the School of Natural Resources and Environment and in the Department of Civil and Environmental Engineering at the University of Michigan and is founder and codirector of the Center for Sustainable Systems. Steven J. Skerlos is associate professor and associate chair of mechanical engineering and director of the Environmental and Sustainable Technologies Laboratory at the University of Michigan.

\section{Supporting Information}

Additional supporting information may be found in the online version of this article:

Supporting Information S1: This supplement contains three tables with data on life cycle greenhouse gas emissions, material substitution, and methods used in both the aluminum and steel industries, as well as vehicle miles traveled (VMT) assumptions as used in the modeling.

Please note: Wiley-Blackwell is not responsible for the content or functionality of any supporting information supplied by the authors. Any queries (other than missing material) should be directed to the corresponding author for the article. 